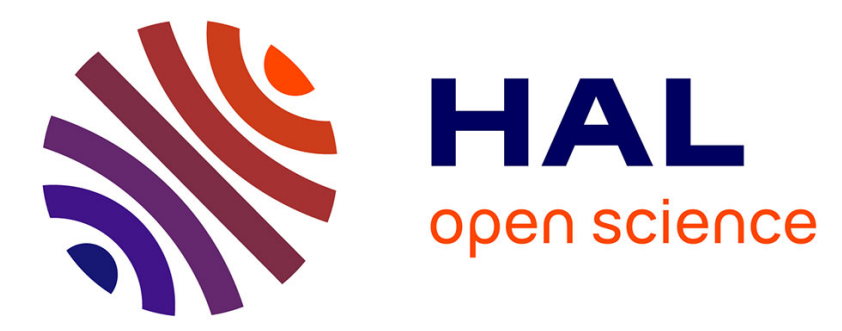

\title{
Effect of trapping and temperature on the hydrogen embrittlement susceptibility of alloy 718
}

Florian Galliano, Eric Andrieu, Christine Blanc, Jean-Marc Cloué, Damien

Connétable, Grégory Odemer

\section{- To cite this version:}

Florian Galliano, Eric Andrieu, Christine Blanc, Jean-Marc Cloué, Damien Connétable, et al.. Effect of trapping and temperature on the hydrogen embrittlement susceptibility of alloy 718. Materials Science and Engineering: A, 2014, vol. 611, pp. 370-382. 10.1016/j.msea.2014.06.015 . hal-01167190

\author{
HAL Id: hal-01167190 \\ https://hal.science/hal-01167190
}

Submitted on 24 Jun 2015

HAL is a multi-disciplinary open access archive for the deposit and dissemination of scientific research documents, whether they are published or not. The documents may come from teaching and research institutions in France or abroad, or from public or private research centers.
L'archive ouverte pluridisciplinaire HAL, est destinée au dépôt et à la diffusion de documents scientifiques de niveau recherche, publiés ou non, émanant des établissements d'enseignement et de recherche français ou étrangers, des laboratoires publics ou privés. 


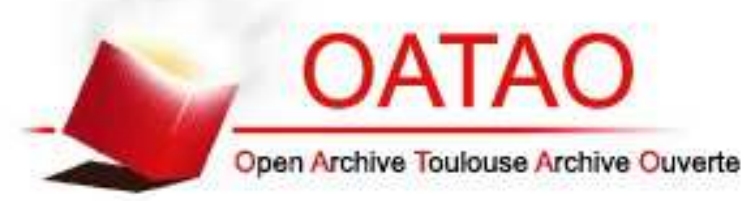

\section{Open Archive TOULOUSE Archive Ouverte (OATAO)}

OATAO is an open access repository that collects the work of Toulouse researchers and makes it freely available over the web where possible.

This is an author-deposited version published in : http://oatao.univ-toulouse.fr/ Eprints ID : 14015

To link to this article : doi: 10.1016/j.msea.2014.06.015

URL : http://dx.doi.org/10.1016/j.msea.2014.06.015

To cite this version : Galliano, Florian and Andrieu, Eric and Blanc, Christine and Cloué, Jean-Marc and Connétable, Damien and Odemer, Grégory Effect of trapping and temperature on the hydrogen embrittlement susceptibility of alloy 718. (2014) Materials Science and Engineering A, vol. 611. pp. 370-382. ISSN 0921-5093

Any correspondance concerning this service should be sent to the repository administrator: staff-oatao@ listes-diff.inp-toulouse.fr 


\title{
Effect of trapping and temperature on the hydrogen embrittlement susceptibility of alloy 718
}

\author{
Florian Galliano, Eric Andrieu, Christine Blanc, Jean-Marc Cloue, Damien Connetable, \\ Gregory Odemer*
}

Université de Toulouse, CIRIMAT, UPS/CNRS/INPT, 4 allée Emile Monso, BP 44362, 31030 Toulouse Cedex 4, France

\begin{abstract}
A B S T R A C T
Ni-based alloy 718 is widely used to manufacture structural components in the aeronautic and nuclear industries. Numerous studies have shown that alloy 718 may be sensitive to hydrogen embrittlement. In the present study, the susceptibilities of three distinct metallurgical states of alloy 718 to hydrogen embrittlement were investigated to identify both the effect of hydrogen trapping on hydrogen embrittlement and the role of temperature in the hydrogen-trapping mechanism. Cathodic charging in a molten salt bath was used to saturate the different hydrogen traps of each metallurgical state. Tensile tests at different temperatures and different strain rates were carried out to study the effect of hydrogen on mechanical properties and failure modes, in combination with hydrogen content measurements. The results demonstrated that Ni-based superalloy 718 was strongly susceptible to hydrogen embrittlement between $25^{\circ} \mathrm{C}$ and $300{ }^{\circ} \mathrm{C}$, and highlighted the dominant roles played by the hydrogen solubility and the hydrogen trapping on mechanical behavior and fracture modes.
\end{abstract}

\section{Introduction}

Alloy 718 is a Ni-based superalloy that is widely used in hightemperature applications, particularly for structural components in the aeronautic and nuclear industries, due to its good mechanical properties and good resistance to stress corrosion cracking. The alloy is strengthened both by structural hardening due to the precipitation of stable $\gamma^{\prime}\left(\mathrm{Ni}_{3}(\mathrm{Ti}, \mathrm{Al})\right)$ and metastable $\gamma^{\prime \prime}\left(\mathrm{Ni}_{3} \mathrm{Nb}\right)$ precipitates and by solid solution hardening [1]. Under the conditions required by certain fabrication processes, the precipitation of a stable form of $\left(\mathrm{Ni}_{3} \mathrm{Nb}\right)$ corresponding to the $\delta$ phase may occur [2]. Under severe operating conditions, corrosion processes may cause local hydrogen enrichment at the material surface. Consequently, a hydrogen-assisted stress corrosion cracking phenomenon can occur under complex stress and strain states [3].

The hydrogen embrittlement of Ni-based alloys is generally exacerbated when the alloys are submitted to mechanical loading, suggesting that hydrogen diffusion occurs along stress gradients and hydrogen transport by dislocations during plastic deformation [4-14]. Hydrogen transport by mobile dislocations can lead to local hydrogen enrichment in the dislocation pile-ups close to precipitates, which favors crack initiation. The fracture modes due to hydrogen embrittlement (HE) are varied, ranging from brittle

\footnotetext{
* Corresponding author. Tel.: +335343234 38; fax: + 33534323498. E-mail address: gregory.odemer@ensiacet.fr (G. Odemer).
}

intergranular to transgranular modes with cleavage facets or ductile character.

Fournier et al. [8] studied the HE susceptibility of strengthened alloy 718 cathodically precharged at room temperature. Due to the observation of planar cleavage microfacets on the fracture surfaces of hydrogen-embrittled specimens, the authors proposed that HE probably occurs by strong hydrogen-deformation interactions, i.e., hydrogen transport by dislocations. In this case, HE would be correlated with hydrogen segregation toward moving dislocations and hydrogen transport in the form of a Cottrell atmosphere around these dislocations. Consequently, at slow strain rates, the dislocation sweeping of hydrogen takes place and HE is more pronounced. In contrast, at a strain rate of $5 \times 10^{-3} \mathrm{~s}^{-1}$, the dislocation velocity is too high to induce significant hydrogen segregation, and thus, HE is reduced.

Some authors have explored the role of precipitates in HE in alloy 718 and particularly the contribution of these precipitates to the hydrogen-trapping mechanism depending on their unique characteristics [5,12-15]. Liu et al. [12] demonstrated that both $\delta$ phase and $\gamma^{\prime \prime}$ phase play significant roles in altering the HE sensitivity of alloy 718 . Hydrogen-induced cracking occurs at $\delta$ or $\gamma^{\prime}-\gamma^{\prime \prime} /$ matrix interfaces and promotes the formation of planar cleavage microfacets on the fracture surfaces of hydrogenembrittled specimens. Young and Scully [15] studied the role of carbides in hydrogen trapping in $\mathrm{Ni}-17 \mathrm{Cr}-8 \mathrm{Fe}$ alloys. The authors demonstrated that mill annealing $\left(<1000{ }^{\circ} \mathrm{C}\right)$ produces strong trap sites $(\approx 55 \mathrm{KJ} / \mathrm{mol}$ binding energy) capable of retaining 
relatively large amounts ( $\approx 1.8 \mathrm{wt} \mathrm{ppm}$ ) of hydrogen, whereas sensitization $\left(600^{\circ} \mathrm{C} / 24 \mathrm{~h}\right)$ produces weaker traps $(19-28 \mathrm{KJ} / \mathrm{mol}$ binding energy) that dissolve less hydrogen ( $\approx 1 \mathrm{wt} \mathrm{ppm}$ ) relative to the amount dissolved by the mill-annealed material. The difference in the trap sites is related to the predominant type of carbide $\left(\mathrm{M}_{7} \mathrm{C}_{3}\right.$ in mill-annealed material vs. $\mathrm{M}_{23} \mathrm{C}_{6}$ in sensitized material). Finally, it was observed that hydrogen trapping on grain boundary carbides promoted the intergranular stress corrosion cracking (SCC) of Ni-Cr-Fe alloys. In alloy 718, carbides that are essentially primary $\mathrm{NbC}$ carbides and $((\mathrm{Nb}, \mathrm{Ti}) \mathrm{C}, \mathrm{N})$ carbonitrides are considered as irreversible traps. Furthermore, Robertson indicated that solubility is strongly affected by the presence of agehardening precipitates and dissolved elements in the matrix of alloy 718 [16].

Concerning the effect of temperature on the HE of Ni-based alloys, the results of different studies vary widely. Some authors have reported only $\mathrm{HE}$ for specimens mechanically loaded at relatively low temperature (below $150{ }^{\circ} \mathrm{C}$ ) [7-9,17]. However, others have shown that the effect of HE could be extended at high temperatures. Fukuyama et al. [10] reported that alloy 718 was still HE-susceptible at $500{ }^{\circ} \mathrm{C}$ under high hydrogen pressures ranging from $1.1 \mathrm{MPa}$ to $19.7 \mathrm{MPa}$. The deleterious effect of hydrogen on the tensile properties of the alloy was enhanced with the $\delta$ phase volume fraction and decreased with temperature. Cracks were initiated at the carbides and then crack propagated along the interface between the $\delta$ phase and $\gamma$ matrix of the alloy or along the grain boundaries of the alloy without $\delta$ phase. Wei et al. [11] studied the effect of gaseous hydrogen on the tensile properties of alloy 718 for high-temperature applications. It was demonstrated that the ductility of a solution-treated and aged compressor disc material was reduced in a hydrogen atmosphere at $300{ }^{\circ} \mathrm{C}$ and $600{ }^{\circ} \mathrm{C}$ and to a lesser extent for a solution-annealed plate material.

The aim of this study was to characterize the effect of hydrogen trapping on the mechanical resistance of precipitates/matrix interfaces in relation to fracture mode for different metallurgical states of alloy 718 . The hydrogen cathodic charging procedure was optimized to saturate the characteristic traps of each metallurgical state with hydrogen. This approach, which suppresses the hydrogen enrichment of traps by a transport mechanism, allowed for the intrinsic resistance of hydrogen-saturated interfaces to be tested. Moreover, the effect of temperature on the reversibility of hydrogen trapping was studied by desorption heat treatments in combination with hydrogen content measurements.

\section{Experimental}

\subsection{Material}

Alloy 718 is a Ni-based superalloy with high contents of iron, chromium and niobium and small amounts of aluminum, titanium and molybdenum. The material tested in the present study was fashioned from a 0.64 -mm-thick strip provided after high temperature recrystallization heat treatment at $1080^{\circ} \mathrm{C}$. The chemical composition of the studied alloy is reported in Table 1.

The typical strengthening heat treatment applied to alloy 718 consists in a dwell of $8 \mathrm{~h}$ at $720^{\circ} \mathrm{C}$, followed by cooling at $50{ }^{\circ} \mathrm{C} / \mathrm{h}$ and a final dwell of $8 \mathrm{~h}$ at $620^{\circ} \mathrm{C}$. This process leads to the precipitation of $\gamma^{\prime \prime}$ (metastable and coherent with the matrix, tetragonal $\mathrm{D0}_{22}$ structure, $\mathrm{Ni}_{3} \mathrm{Nb}$ composition, disc-shaped $(20 \mathrm{~nm}$ diameter $\times 10 \mathrm{~nm}$ thickness)) and $\gamma^{\prime}$ (stable and coherent with the matrix, cubic $\mathrm{L}_{2}$ structure, $(\mathrm{Al}, \mathrm{Ti}) \mathrm{Ni}_{3}$ composition, spherical shape $(20 \mathrm{~nm})$ ) phases embedded in a $\gamma$ matrix (volume fraction of $\gamma^{\prime}-$ $\gamma^{\prime \prime}=16 \%$ and $\gamma^{\prime} / \gamma^{\prime \prime}$ ratio $=1 / 4$ ). Semi-incoherent $\delta$ particles (stable form of $\gamma^{\prime \prime}$ phase, globular or needle-shaped ( $\left.>1 \mu \mathrm{m}\right)$ ) may also be observed, depending on fabrication processes employed.

Because all precipitates and inclusions may potentially act as hydrogen traps, three "model" metallurgical states were synthesized to distinguish the effect of each population of traps on the hydrogen embrittlement susceptibility of alloy 718 :

- The first metallurgical state corresponded to the as-received alloy 718 obtained after high temperature recrystallization heat treatment (RHT) at $1080^{\circ} \mathrm{C}$. In this state, the alloy presented only two phases, the solid solution and primary carbides $\mathrm{NbC}$ and ((Nb,Ti)C,N) (Fig. 1a)

- The second metallurgical state, called HT, corresponded to a material strengthened by the previously described aging heat treatment. Representative TEM micrographs of the metallurgical state are presented in Fig. $1 \mathrm{~b}$ and c. No $\delta$ phase was observed in the grain boundaries. $\gamma^{\prime} / \gamma^{\prime \prime}$ precipitates were clearly observed (Fig. 1c) and were homogeneously distributed. Primary carbides precipitates were still present.

- The last metallurgical state was obtained by a preliminary heat treatment at $960{ }^{\circ} \mathrm{C}$ for $48 \mathrm{~h}$ to precipitate intragranular and intergranular platelets and globular $\delta$ phases (Fig. 1d). This preliminary heat treatment was followed by the standard aging treatment previously described. Therefore, in addition to $\gamma^{\prime} / \gamma^{\prime \prime}$ and carbide precipitates, $\delta$ phase was observed. For this metallurgical state, called $\delta$-HT, the $\delta$ phase surface fraction was increased to $9 \%$.

For the three metallurgical states RHT, HT and $\delta$-HT, corresponding samples presented a homogeneous grain size of ASTM 910. Table 2 gathers the different microstructural details of each metallurgical state.

\subsection{Hydrogen charging}

Hydrogen was introduced into the material at $150{ }^{\circ} \mathrm{C}$ by an electrochemical charging method in a eutectic mixture of molten salts $\left(\mathrm{NaHSO}_{4} \cdot \mathrm{H}_{2} \mathrm{O} 53.5 \mathrm{wt} \%-\mathrm{KHSO}_{4} 46.5 \mathrm{wt} \%\right.$ ) as described by Larignon et al. [18]. This electrochemical technique consists in the electrolysis of water in a molten salt bath using a three-electrode system:

Anodic reaction : $\mathrm{H}_{2} \mathrm{O}+2 \mathrm{SO}_{4}{ }^{2-} \rightarrow 2 \mathrm{HSO}^{-}+\frac{1}{2} \mathrm{O}_{2}+2 e^{-}$

Cathodic reaction : $\mathrm{HSO}_{4}{ }^{-}+e^{-} \rightarrow \mathrm{H}_{\mathrm{ads}}+\mathrm{SO}_{4}{ }^{2-}$

The potential of the sample (working electrode) is measured with respect to a silver electrode situated close to the sample and maintained at a constant cathodic voltage of $-1 \mathrm{~V}$. The reference electrode composed of $\mathrm{Ag} / \mathrm{Ag}^{+}$in Pyrex, consisting of an $\mathrm{Ag}$ wire immersed in a small volume of molten salts and separated from the bath by means of a Luggin capillary, was connected to a potentiostat to monitor any change in the potential of the working

Table 1

Chemical composition of studied alloy 718 (wt\%).

\begin{tabular}{lllllllllllllllllll}
\hline $\mathbf{N i}$ & Cr & Fe & Nb & Mo & Ti & AI & Mn & Si & C & Cu & Co & Ta & P & B & S & & & \\
\hline 53.66 & 18.39 & 18.31 & 4.94 & 3.00 & 0.95 & 0.56 & 0.06 & 0.04 & 0.033 & 0.02 & 0.02 & 0.01 & 0.005 & 0.002 & 0.0002 \\
\hline
\end{tabular}



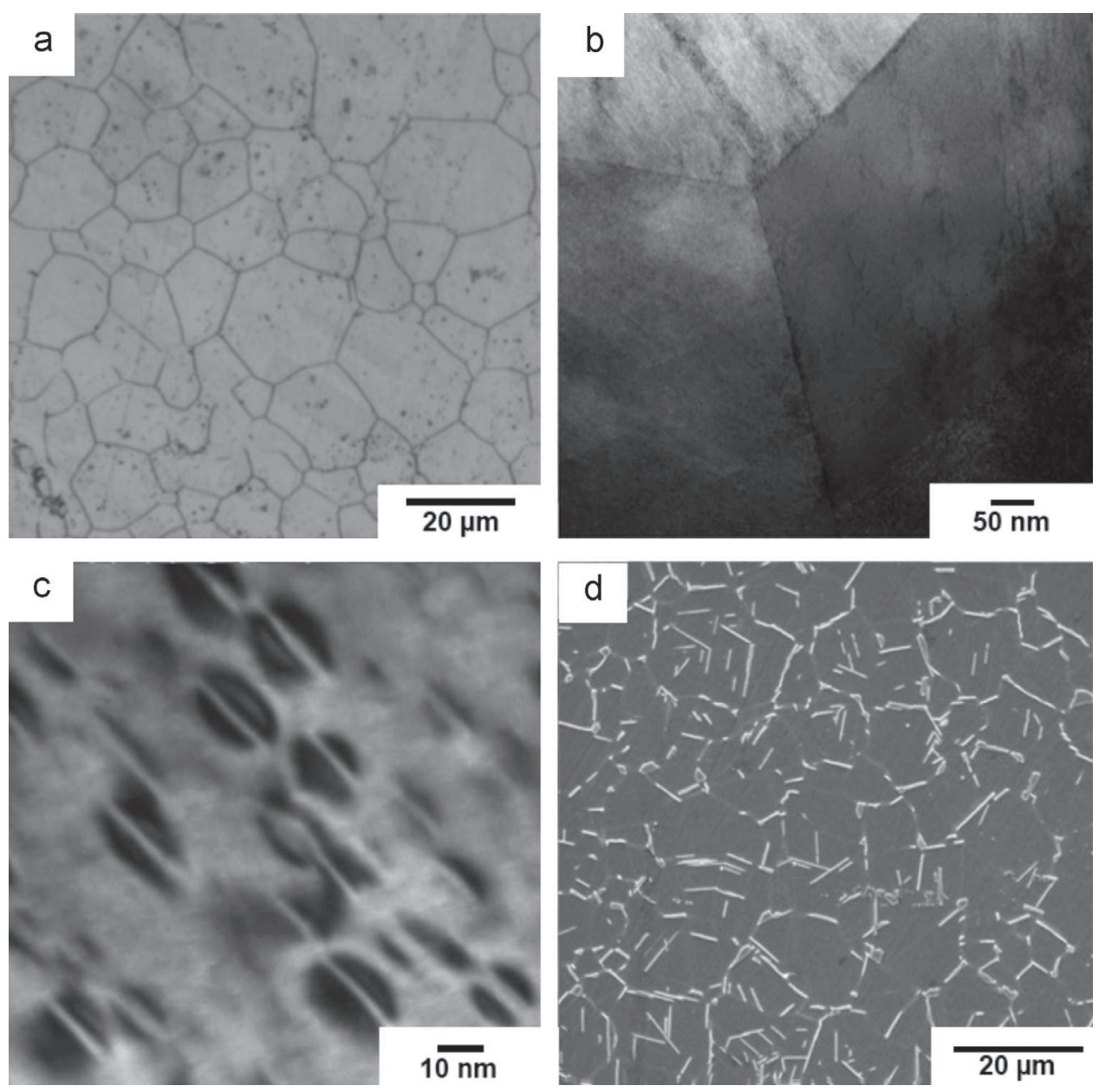

Fig. 1. Microstructural observations of (a) metallurgical state RHT - optical micrograph; (b, c) metallurgical state HT - TEM micrographs; (d) metallurgical state $\delta$-HT - SEM micrograph.

Table 2

Summary of the different microstructural characteristics of each metallurgical state of alloy 718 considered.

\begin{tabular}{lll}
\hline Metallurgical state & Heat treatment & Expected hydrogen traps \\
\hline RHT & Recrystallization heat treatment $\left(1080^{\circ} \mathrm{C}\right.$ ) & Carbides, grain boundaries ("short-circuit” path of diffusion) \\
HT & $720^{\circ} \mathrm{C} / 8 \mathrm{~h}$, cooling at $50^{\circ} \mathrm{C} / \mathrm{h}, 620^{\circ} \mathrm{C} / 8 \mathrm{~h}$ & $\begin{array}{l}\gamma^{\prime}, \gamma^{\prime \prime}, \text { carbides, grain boundaries ("short-circuit" path of diffusion) } \\
\gamma^{\prime}, \gamma^{\prime \prime}, \text { large } \delta \text { precipitates, carbides, grain boundaries ("short-circuit" path of diffusion) }\end{array}$ \\
\hline
\end{tabular}

electrode. A known amount of $\mathrm{Ag}^{+}$, i.e., $1 \mathrm{M}$, was added to the reference compartment in the form of $\mathrm{AgNO}_{3}$. Considering that the silver electrode is progressively consumed during the experiment in the corrosive molten salt bath, the electrode material is referred to as $\mathrm{Ag} / \mathrm{Ag}^{+}$. The current necessary to hold the cathodic potential at a constant value was controlled by the Voltamaster potentiostat by an auxiliary Pt-electrode placed around the sample. Under these conditions the anodic and cathodic reactions are equivalent to the electrolysis of the water in the bath as previously reported. The surface area of the Pt electrode was 10 times the sample surface area. The applied cathodic potential for all metallurgical states, i.e., $-1 \mathrm{~V}$, was chosen in such that the value was located in the middle of the cathodic plateau, as determined by a preliminary potentiokinetic polarization test performed on the working electrode in a molten salt bath. All specimens and holders, except for the surfaces intended for charging, were coated by a thermalresistant silicone sealant to prevent any galvanic reaction.

Different hydrogen-charging durations were applied to vary the hydrogen content and therefore the degree of saturation of the traps. After hydrogen charging, the specimens were stored in liquid nitrogen to prevent hydrogen desorption. Hydrogen content measurements were performed after each step of the hydrogencharging process by using coupons taken from the tensile specimen heads. The measurements confirmed the reproducibility of the cathodic charging technique over a given charging time.

\subsection{Hydrogen content measurements}

The hydrogen content was measured using a Galileo Bruker analyzer. Hydrogen was extracted by the fusion $\left(1550^{\circ} \mathrm{C}\right)$ of each sample in inert gas (Argon) and analyzed by a high-sensitivity thermal conductivity detector. This method consisted in first placing the sample in a graphite crucible. Then, the sample was heated in an impulse furnace by passing a high current through the crucible. The gas desorbed from the material during melting was analyzed by the differential thermal conductivity detector after the removal of dust and moisture. 


\subsection{Desorption treatments}

Hydrogen desorption treatments were performed on hydrogenprecharged specimens at four temperatures: $25^{\circ} \mathrm{C}, 80^{\circ} \mathrm{C}, 150^{\circ} \mathrm{C}$ and $320^{\circ} \mathrm{C}$. The kinetics of the desorption treatments were monitored by measuring the hydrogen content in the samples at different desorption times. The aim of this approach was to study both the reversibility of hydrogen trapping in relation to the trap type and the diffusible hydrogen desorption in the different metallurgical states.

\subsection{Characterization of mechanical properties of hydrogenated specimen}

Tensile tests were performed at two different strain rates, i.e., a slow strain rate of $5 \times 10^{-4} \mathrm{~s}^{-1}$ and a high strain rate of $10^{-1} \mathrm{~s}^{-1}$, on flat tensile specimens $(0.64 \mathrm{~mm}$ in thickness) with a MTS testing machine equipped with a $5-\mathrm{kN}$ load cell.

For each hydrogen-charging time, three tensile specimens were tested to verify the reproducibility of the results. HE susceptibility was quantified by means of an embrittlement index $\left(I_{E}\right)$ related to the loss of the elongation to failure:

$I_{E}=\frac{\varepsilon_{f_{0}}-\varepsilon_{f_{H}}}{\varepsilon_{f_{0}}} \times 100$

where $\varepsilon_{f_{0}}$ and $\varepsilon_{f_{H}}$ are, respectively, the elongation to failure of the $\mathrm{H}$-free and the hydrogenated tensile samples.

\subsection{Scanning Electron Microscope (SEM) observations}

Microstructure observations were carried out with a LEO 435VP SEM and a JEOL 7000F FEG SEM. Elemental spot analysis was performed using an energy dispersive X-ray spectrometer (EDX).

\section{Results and discussion}

\subsection{Effect of cathodic charging time on diffusion, solubility and} trapping of hydrogen

As mentioned in the introduction, samples were hydrogenated by a cathodic method in molten salts at $150{ }^{\circ} \mathrm{C}$ to saturate hydrogen traps and test the resistance of hydrogen traps/matrix interfaces.

First, diffusion calculations were performed using Fick's second law (transitory regime) for a semi-infinite system to determine the minimal charging time that ensures hydrogen diffusion up to the center of the specimen, i.e., $0.32 \mathrm{~mm}$.

$\frac{C(x)-C_{S}}{C_{0}-C_{S}}=\operatorname{erf}\left(\frac{x}{2 \sqrt{D t}}\right)$

where $D$ is the hydrogen diffusion coefficient (considered to be constant at a given temperature), $t$ is the charging time, $C(x)$ is the hydrogen concentration at depth $x, C_{0}$ is the initial hydrogen concentration $\left(C_{0}(t=0)=0\right)$ and $C_{S}$ is the surface hydrogen concentration $\left(C_{S}(t=0)=1\right)$.

Robertson, in a study on hydrogen permeation and diffusion in alloy 718, identified two expressions for the hydrogen diffusion coefficient in the RHT and HT metallurgical states, which are quite comparable [16].

In this study, the following expression for $D$ was used, according to the results of Robertson regarding the HT metallurgical state [16]:

$D=6.8 \times 10^{-3} \exp \left(\frac{-49500}{R T}\right)\left(\mathrm{cm}^{2} \mathrm{~s}^{-1}\right)$

The results of the diffusion calculations are presented in Fig. 2 for different charging times and for a temperature of $150{ }^{\circ} \mathrm{C}$, which is a

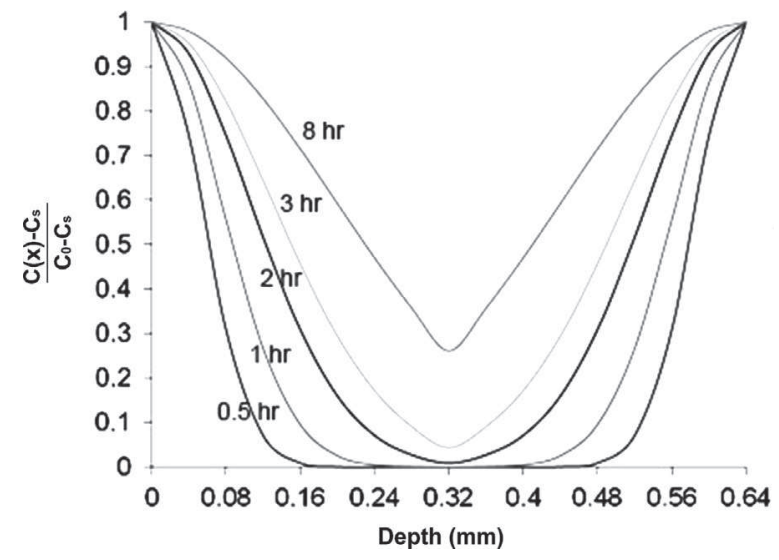

Fig. 2. Hydrogen diffusion profiles at $150{ }^{\circ} \mathrm{C}$ for different charging times $(0.5 \mathrm{~h}, 1 \mathrm{~h}$, $2 \mathrm{~h}, 3 \mathrm{~h}, 8 \mathrm{~h})$.

good compromise from an experimental point of view, considering the charging method used in this work.

These results suggested that a minimal charging time of $8 \mathrm{~h}$ was necessary to ensure sufficient hydrogen diffusion up to the center of the specimen.

After this first step, different cathodic charging times were tested, from $8 \mathrm{~h}$ to $27 \mathrm{~h}$, followed by hydrogen content measurements to choose the most appropriate charging time, i.e., the shortest time inducing hydrogen trap saturation (Fig. 3).

According to Robertson's study [16], the apparent hydrogen solubility is higher for the RHT than for the HT and $\delta$-HT metallurgical states. As a matter of fact, the precipitation of $\gamma^{\prime}-\gamma^{\prime \prime}$ and $\delta$ precipitates induces a decrease in hydrogen solubility in alloy 718 . This result can be explained by the combination of two factors. The first is based on the low solubility of hydrogen in $\gamma^{\prime \prime}$ and $\delta$ precipitates at the temperatures used and on the volume in which hydrogen can be dissolved, which is reduced by the volume ratio of precipitates [19]. This phenomenon is magnified by the fact that, for the HT and $\delta$-HT metallurgical states, the majority of the $\mathrm{Nb}$ and $\mathrm{Ti}$ is tied up in the agehardening precipitates. However, in the RHT material, these elements are dissolved in the matrix, where they may exert their maximum effect in promoting the dissolution of hydrogen in the matrix.

The second factor is based on the observation that the hydrogen solubility decreased beyond $17 \mathrm{~h}$ independent of the metallurgical states. This result suggested that the different metallurgical states were saturated in hydrogen within this charging time. However, the observation of samples after cathodic charging beyond $17 \mathrm{~h}$ revealed surface damage combined with the presence of microcracks, probably due to the strong stresses induced by the high hydrogen content in the subsurface. The presence of numerous microcracks induced a loss of matter at the sample surface that was assumed to lead to the decrease in hydrogen content, considering that hydrogen accumulation was mainly localized in the subsurface.

Given these preliminary results, it was decided that the charging time should be limited to $8 \mathrm{~h}$ to avoid sample damage and to ensure that each metallurgical state is sufficiently saturated with hydrogen. For a better understanding of the hydrogen desorption phenomena occurring during tensile tests performed at different temperatures, desorption heat treatments were preliminarily carried out in conjunction with hydrogen content measurements.

\subsection{Effect of temperature on hydrogen desorption}

Given that alloy 718 is widely used in industry in the HT metallurgical state and that it is the metallurgical state presenting all the types of hydrogen traps, desorption heat treatments were conducted at different temperatures for HT samples cathodically 


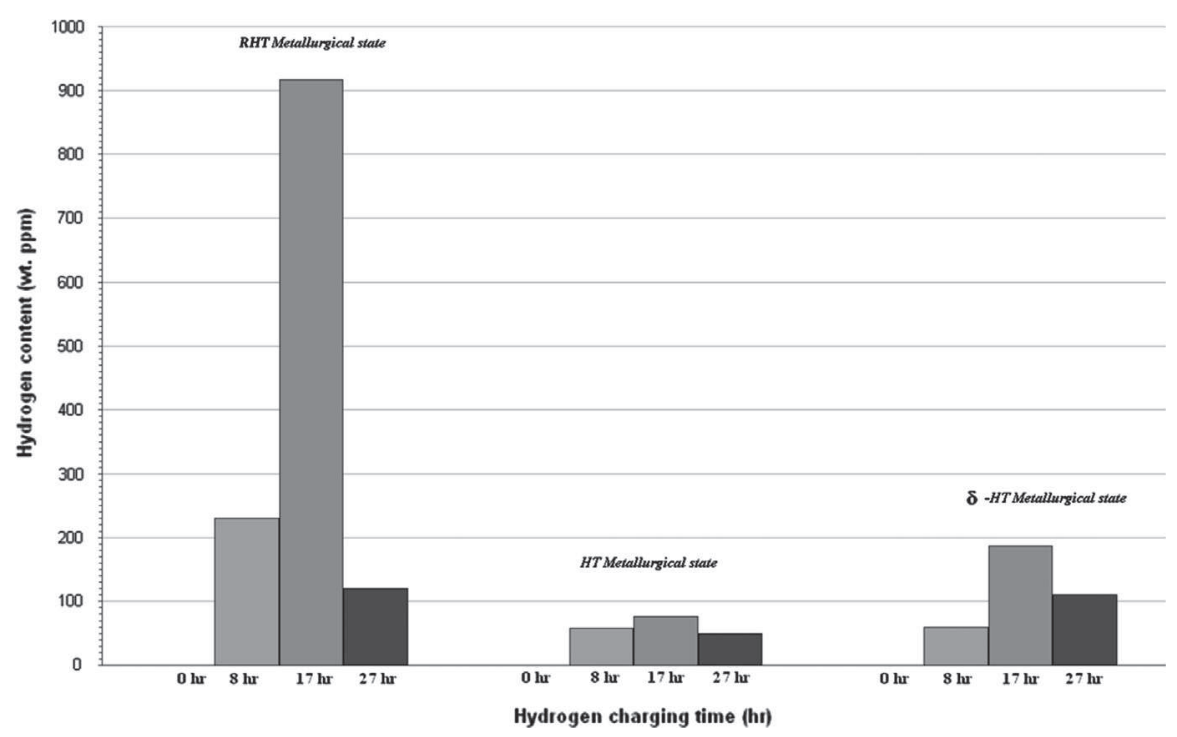

Fig. 3. Evolution of hydrogen content in alloy 718 in RHT, HT and $\delta$-HT metallurgical states after different charging times, i.e., 0.5 h, 8 h, $17 \mathrm{~h}$ and $27 \mathrm{~h}$.

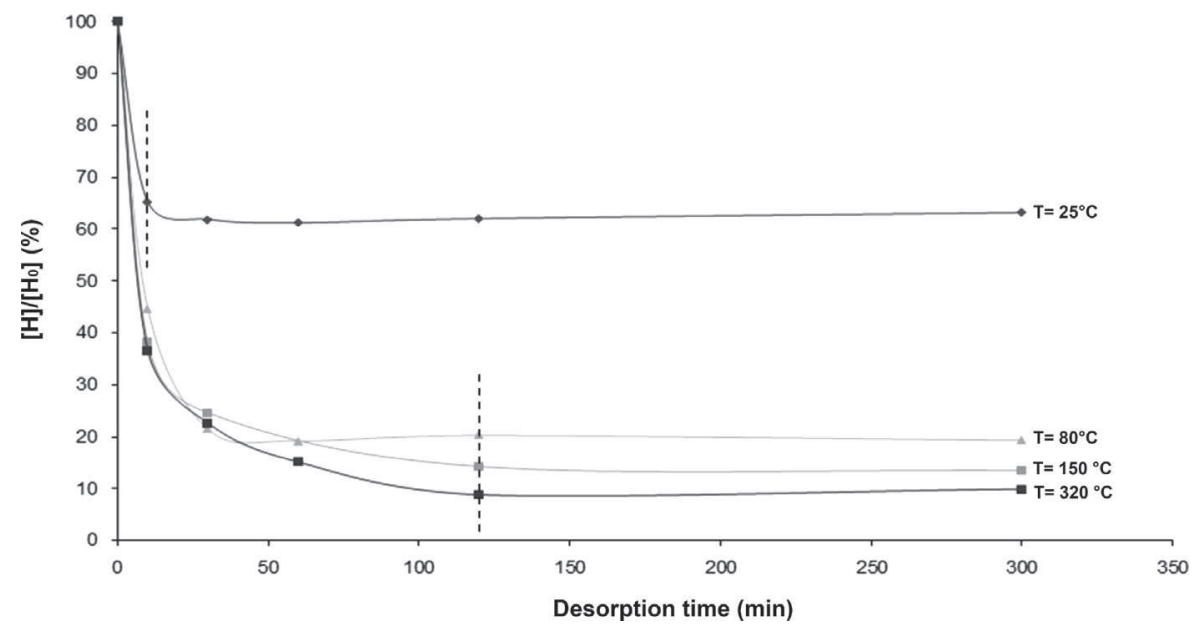

Fig. 4. Evolution of hydrogen content in alloy 718 in HT metallurgical state over 300 min at $25^{\circ} \mathrm{C}, 80^{\circ} \mathrm{C}, 1500^{\circ} \mathrm{C}$ and $320^{\circ} \mathrm{C}$.

pre-hydrogenated for $8 \mathrm{~h}$ at $150^{\circ} \mathrm{C}$ (Fig. 4). To compare the evolution of the hydrogen content between each desorption temperature, the hydrogen content was measured relative the initial hydrogen content obtained immediately after cathodic charging for $8 \mathrm{~h}$ at $150{ }^{\circ} \mathrm{C}$ (Fig. 4).

For all of the temperatures, two successive regimes were characterized. A preliminary step characterized by strong hydrogen desorption followed by a second step corresponding to a stagnation of the hydrogen content:

- Hydrogen desorption regime: $[0-20 \mathrm{~min}]$ at $25^{\circ} \mathrm{C}$ and $[0-$ $120 \mathrm{~min}$ l from $80^{\circ} \mathrm{C}$ to $320^{\circ} \mathrm{C}$.

The hydrogen desorption was relatively rapid, and the level of desorption was affected by the temperature. As the temperature increased, the effect of the desorbed hydrogen content was enhanced due to the increase in the hydrogen diffusion coefficient and solubility with temperature. Considering that the main hydrogen traps characteristic of each metallurgical state, i.e., carbides and strengthening precipitates/matrix interfaces, are irreversible, the rapid hydrogen content decrease observed in the desorption curves was related to the partial desorption of interstitial hydrogen and of hydrogen trapped in grain boundaries, which are considered short-circuit paths of diffusion. This notion was confirmed by the fact that the hydrogen desorption curves for the three metallurgical states somewhat quasi similar at a given temperature.

- Hydrogen content stagnation regime: [20-300 min] at $25^{\circ} \mathrm{C}$ and [120-300 $\mathrm{min}$ ] from $80^{\circ} \mathrm{C}$ to $320^{\circ} \mathrm{C}$

The different dwells obtained for each temperature correspond to the hydrogen still present in the lattice and in grain boundaries and to the hydrogen trapped on $\gamma^{\prime}-\gamma^{\prime \prime}$ or $\delta$ precipitates /matrix interfaces and carbides.

These results regarding hydrogen desorption clearly confirmed that precipitates/matrix interfaces were saturated in hydrogen during the tensile tests, even for those performed at elevated temperature, given that hydrogen desorption is mainly due to the partial desorption of interstitial hydrogen and of hydrogen trapped in grain boundaries. Therefore, the tensile tests performed on cathodically pre-hydrogenated samples were useful in characterizing the mechanical resistance of precipitates/matrix interfaces saturated in hydrogen.

\subsection{Effect of hydrogen on fracture modes in relation with hydrogen trapping}

SEM observations of the fracture surfaces after tensile tests performed for a strain rate of $5 \times 10^{-4} \mathrm{~s}^{-1}$ at room temperature are 

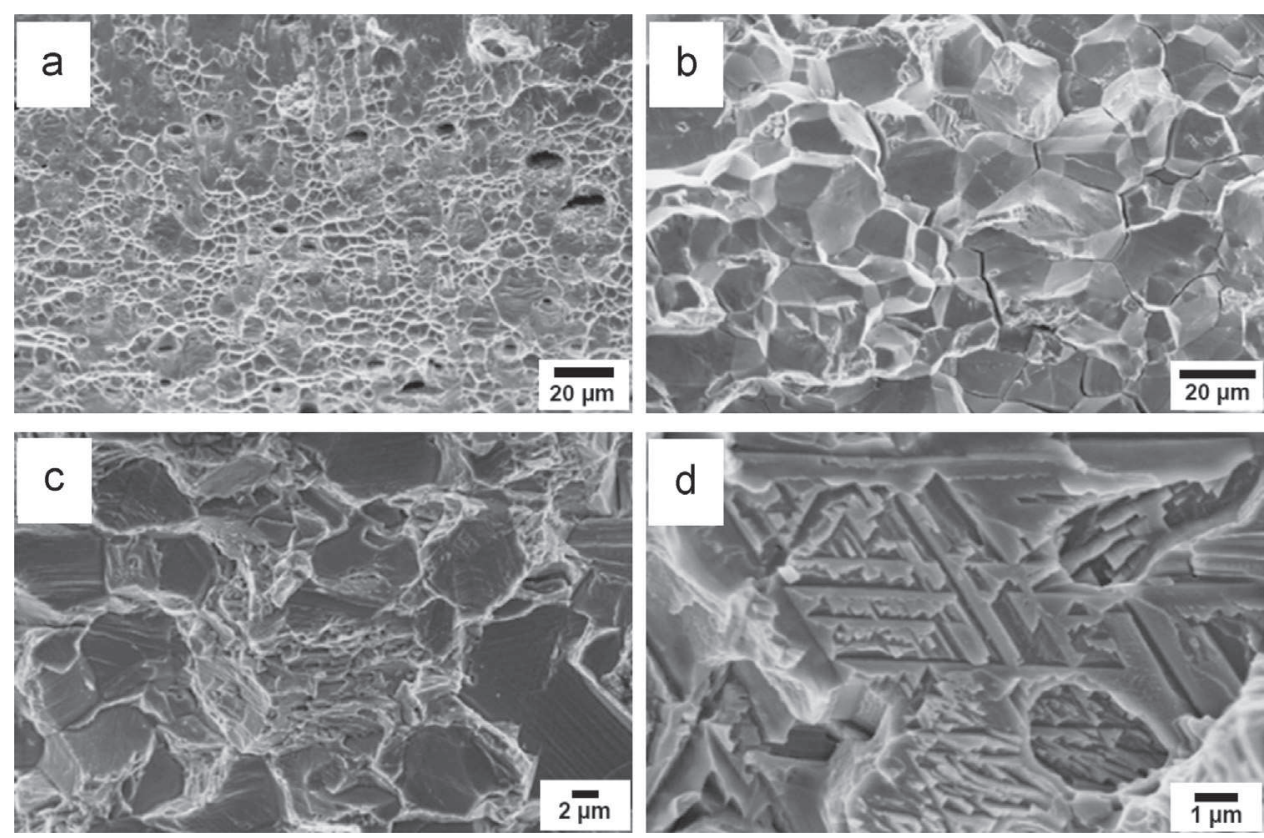

Fig. 5. Fracture surfaces observed by SEM of (a) H-free sample (representative of RHT, HT and $\delta$-HT states), (b) hydrogenated RHT state, (c) hydrogenated HT state and (d) hydrogenated $\delta$-HT state.

presented in Fig. 5 for the three metallurgical states. Fig. 5a presents the fracture mode of one $\mathrm{H}$-free sample that is representative of the ductile fracture mode observed for the three $\mathrm{H}$-free microstructures. Fig. 5(b), (c) and (d) shows the fracture surfaces of the alloy 718 in the RHT, HT and $\delta$-HT metallurgical states, respectively, after hydrogen charging.

The metallurgical state was observed to have a large effect on the fracture modes of the hydrogenated samples tested at room temperature. The fracture surfaces showed:

- Predominant intergranular brittle fracture for the RHT material (Fig. 5b);

- Both intergranular and transgranular (cleavage) brittle fracture for the HT state (Fig. 5c);

- Both intergranular and transgranular brittle (cleavage) fracture for the $\delta$-HT metallurgical state (Fig. 5d). A comparison of SEM observations (Fig. 5d) and EDX mapping (Fig. 6) showed that Nb-rich $\delta$ precipitates (shown in blue in the cartography, Fig. 6) were responsible for $\delta$ precipitate/matrix interface decohesion.

Finally, hydrogen embrittlement observed at the center of the tensile fracture surfaces confirmed that cathodic charging for $8 \mathrm{~h}$ at $150{ }^{\circ} \mathrm{C}$ was sufficient to ensure hydrogen diffusion up to the center of the tensile specimens according to preliminary calculations.

All of the aforementioned results are in relative good agreement with those observed under air testing conditions by Fournier et al. [8] and Liu et al. [14]. Indeed, two main HE mechanisms in relation to the hydrogen-trapping mechanism are generally considered to explain the fracture surfaces observed for the different metallurgical states: the hydrogen-enhanced localized plasticity (HELP) and hydrogen-induced decohesion (HID) mechanisms [20]. The HELP mechanism corresponds to an increase in dislocation mobility by the reduction of the elastic interactions between obstacles and perfect and partial dislocations [21]. Associated with a hydrogen transport phenomenon facilitated by dislocations, this mechanism leads to local segregation of hydrogen on $\{111\}$ planes, inducing cleavage, as well as the decohesion of particles/matrix interfaces (HID mechanism) [22,23]. Fig. 6 shows particularly well the susceptibility of the $\{111\}$ planes to cleavage in the presence of hydrogen.
Concerning the as-received metallurgical state, intergranular brittle fracture suggested that hydrogen preferentially diffused/ segregated along grain boundaries, ultimately due to the hydrogen-trapping mechanism on carbides, and reduced the cohesive strength of the grain boundaries' structure. Moreover, the grain boundary chemistry and crystallographic relations could have a strong effect on HE susceptibility, and the possibility of intergranular segregations is currently being studied. Indeed, even if carbides are recognized as irreversible traps, there are too few of these particles in the grain boundaries to explain the high susceptibility to intergranular rupture in the presence of hydrogen. However, the location of these carbides could allow them to play a more prominent role than expected simply based on their concentration [24]. Hydrogen has been shown to segregate to grain boundaries in $\mathrm{Ni}$ and is likely to behave similarly in Ni-based alloys [25]. Thus, even though the grain boundary carbides are present in a relatively small amount, their concentration in a region where hydrogen segregates could allow them to make a sizable contribution to trapping.

Another possibility is that the irreversible traps, i.e., carbides, are associated with another element segregated at grain boundaries, for example, $\mathrm{Nb}$ or P. Although some works doubt that grain boundary segregants play a major role in the intergranular cracking of this alloy [26-28], other works [16] have shown that hydrogen solubility was enhanced by element segregation that could indirectly favor the intergranular rupture by a decohesion mechanism. This point is actually studied by in-situ local detection techniques and ab-initio calculations.

\subsection{Effect of hydrogen on residual mechanical properties at room temperature}

The mechanical properties of the uncharged specimen in alloy 718 were determined at room temperature at a strain rate of $5 \times 10^{-4} \mathrm{~s}^{-1}$. The results are presented in Table 3. It was verified that the tensile mechanical behavior of alloy 718 for all studied metallurgical states was not affected by the time spent at $150{ }^{\circ} \mathrm{C}$ during the cathodic precharging. The evolution of the mechanical properties monitored after hydrogen charging in a molten salt 

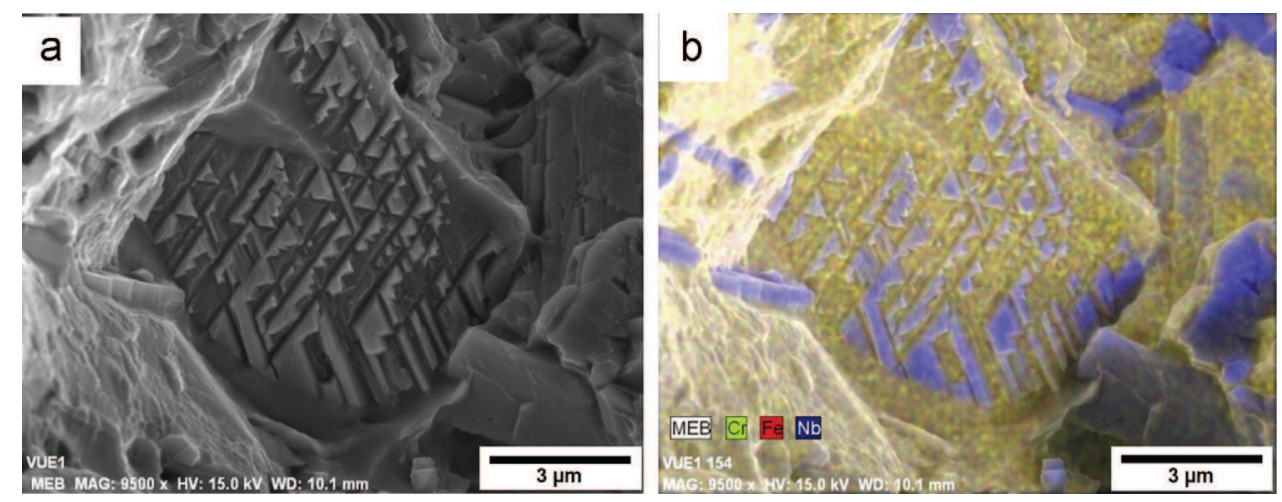

Fig. 6. (a) SEM image of cleavage microfacet and (b) EDS mapping (SEM) of the fracture surface of $\delta$-HT metallurgical state. (For interpretation of the references to color in this figure, the reader is referred to the web version of this article.)

bath at $150^{\circ} \mathrm{C}$ is therefore due to the hydrogen absorption in the material.

The results showed an enhancement in the mechanical properties due to the structural hardening related to the precipitation of $\gamma^{\prime}$ and $\gamma^{\prime \prime}$ particles (HT). As expected, the precipitation of $\delta$ phase reduced the global mechanical properties due to a decrease in the volume fraction of $\gamma^{\prime \prime}$ particles in alloy 718. More precisely, this effect could be explained by the presence of a $\gamma^{\prime \prime}$-free zone around $\delta$ precipitates.

The mechanical properties evaluated at room temperature for tensile samples hydrogenated for $8 \mathrm{~h}$ at $150^{\circ} \mathrm{C}$, according to the results discussed in the first part of this paper, are summarized in Table 4. The hydrogen content before tensile tests and embrittlement index $\left(I_{E}\right)$ are also presented. The results indicate a strong influence of hydrogen at room temperature on elongation to failure for all of the metallurgical states.

In this study, the HT metallurgical state presented a volume fraction of $\left(\gamma^{\prime}+\gamma^{\prime \prime}\right)$ of approximately $16 \%$ with a $\gamma^{\prime} / \gamma^{\prime \prime}$ ratio equal to $1 / 4$ according to the works of Liu et al. [12] who showed that the HE susceptibility of alloy 718 in the HT metallurgical state was correlated with the volume fraction of strengthening particles. Indeed, it has been demonstrated in various studies that $\gamma^{\prime}$ or $\gamma^{\prime \prime} \mid$ matrix interfaces are strong hydrogen traps for strengthened alloy 718 [14].

Concerning the $\delta$-HT metallurgical state, the presence of $\delta$ phase has a deleterious effect on mechanical properties in the presence of hydrogen. Once again, this finding is consistent with the results of Liu et al. concerning the effect of $\delta$ phase on the HE susceptibility of alloy 718 [12], which is known as a potential hydrogen trap.

The RHT metallurgical state was also very sensitive to hydrogen, with an embrittlement index of $95 \%$. This result is relatively different from the results obtained by Liu et al. [14], who showed that the intrinsic HE of the nickel-based matrix, as well as the HE from carbides, is insignificant when neither $\gamma^{\prime} / \gamma^{\prime \prime}$ nor $\delta$ particles exist. To explain this difference, it can be assumed that the high hydrogen content measured for the RHT metallurgical state combined with the presence of carbides, known as irreversible hydrogen traps [15], is probably responsible for the high HE susceptibility of this microstructure.

Given that tensile specimen ruptures occurred at the UTS, it is interesting to plot the evolution of elongation to failure vs. UTS for $\mathrm{H}-$ free and $\mathrm{H}$-charged samples of each metallurgical state (Fig. 7). This plot suggests the existence of a critical stress level leading to a premature rupture in the presence of hydrogen that could be related to the activation of new rupture modes, i.e., cleavage and intergranular rupture, induced by hydrogen trapping for each metallurgical state. The critical stress inducing $\delta$ precipitate/matrix interface decohesion appears to be lower than the critical stress inducing the formation of
Table 3

Mechanical properties of $\mathrm{H}$-free specimens in alloy 718 at room temperature (strain rate $5 \times 10^{-4} \mathrm{~s}^{-1}$ ) for RHT, HT and $\delta$-HT metallurgical states.

\begin{tabular}{|c|c|c|c|c|}
\hline Metallurgical state & $\varepsilon_{f}(\%)$ & YS (MPa) & UTS (MPa) & [H] (wt ppm) \\
\hline RHT & 46 & 420 & 750 & 0.4 \\
\hline HT & 23 & 1220 & 1400 & 0.5 \\
\hline$\delta-\mathrm{HT}$ & 23 & 750 & 1100 & 0.4 \\
\hline
\end{tabular}

Table 4

Mechanical properties, hydrogen content before tensile tests $\left(5 \times 10^{-4} \mathrm{~s}^{-1}\right)$ and embrittlement index at room temperature of hydrogenated specimens in alloy 718 in RHT, HT and $\delta$-HT metallurgical states.

\begin{tabular}{lccccc}
\hline Metallurgical state & $\varepsilon_{f}(\%)$ & YS (MPa) & UTS (MPa) & {$[\mathrm{H}](\mathrm{wt} \mathrm{ppm})$} & $I_{E}(\%)$ \\
\hline RHT & 2.2 & 450 & 555 & 230 & 95 \\
HT & 0.6 & 1210 & 1330 & 58 & 97 \\
$\delta$-HT & 1.0 & 780 & 955 & 60 & 96 \\
\hline
\end{tabular}

$\gamma^{\prime}-\gamma^{\prime \prime}$ particles/matrix interfaces and intergranular rupture when hydrogen traps are saturated. Moreover, the hydrogen solubility is probably a first-order parameter that likely affects this critical stress and particularly the critical stress inducing grain boundary rupture. Indeed, numerous studies have shown that grain boundaries are preferential short-circuit paths of diffusion for hydrogen. In addition, the intergranular segregation of elements such as $\mathrm{Nb}$ or $\mathrm{P}$ could enhance hydrogen solubility [16,29].

To conclude this section on the role of hydrogen solubility in determining mechanical properties, it is interesting to recall a previous result presented in this paper that suggested that hydrogen solubility was a first-order parameter concerning the existence of a critical rupture stress inducing cleavage in the matrix and strengthening particle/matrix decohesion. Indeed, it was shown that the high hydrogen solubility obtained for long cathodic charging times induced surface damage in samples. This finding was explained by the strong stresses induced by the high interstitial hydrogen content under the subsurface exposed during cathodic charging.

The last point made regarding the effect of hydrogen on mechanical properties is associated with the effect of strain hardening. Fig. 8 presents the evolution of strain hardening (UTS-YS) as a function of YS. It can be observed that in the presence of hydrogen, the contribution of strain hardening is necessary to obtain fracture regardless of the initial yield stress. This result strongly suggests that plastic deformation is needed to reach the critical rupture stresses of the weakest traps. It should be recalled tensile tests 


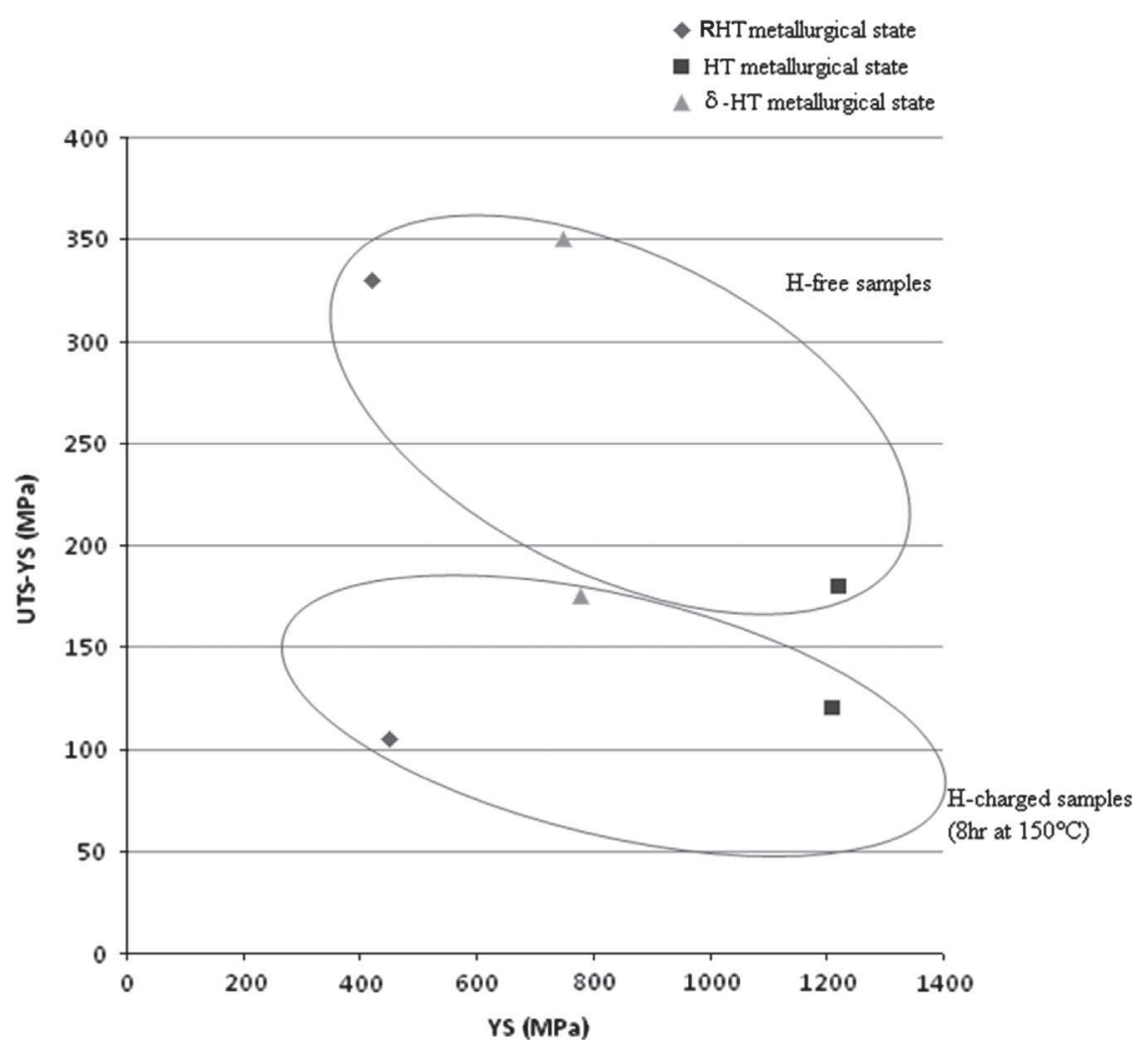

Fig. 7. Evolution of elongation to failure vs. UTS for H-free and H-charged samples of RHT, HT and $\delta$-HT metallurgical states.

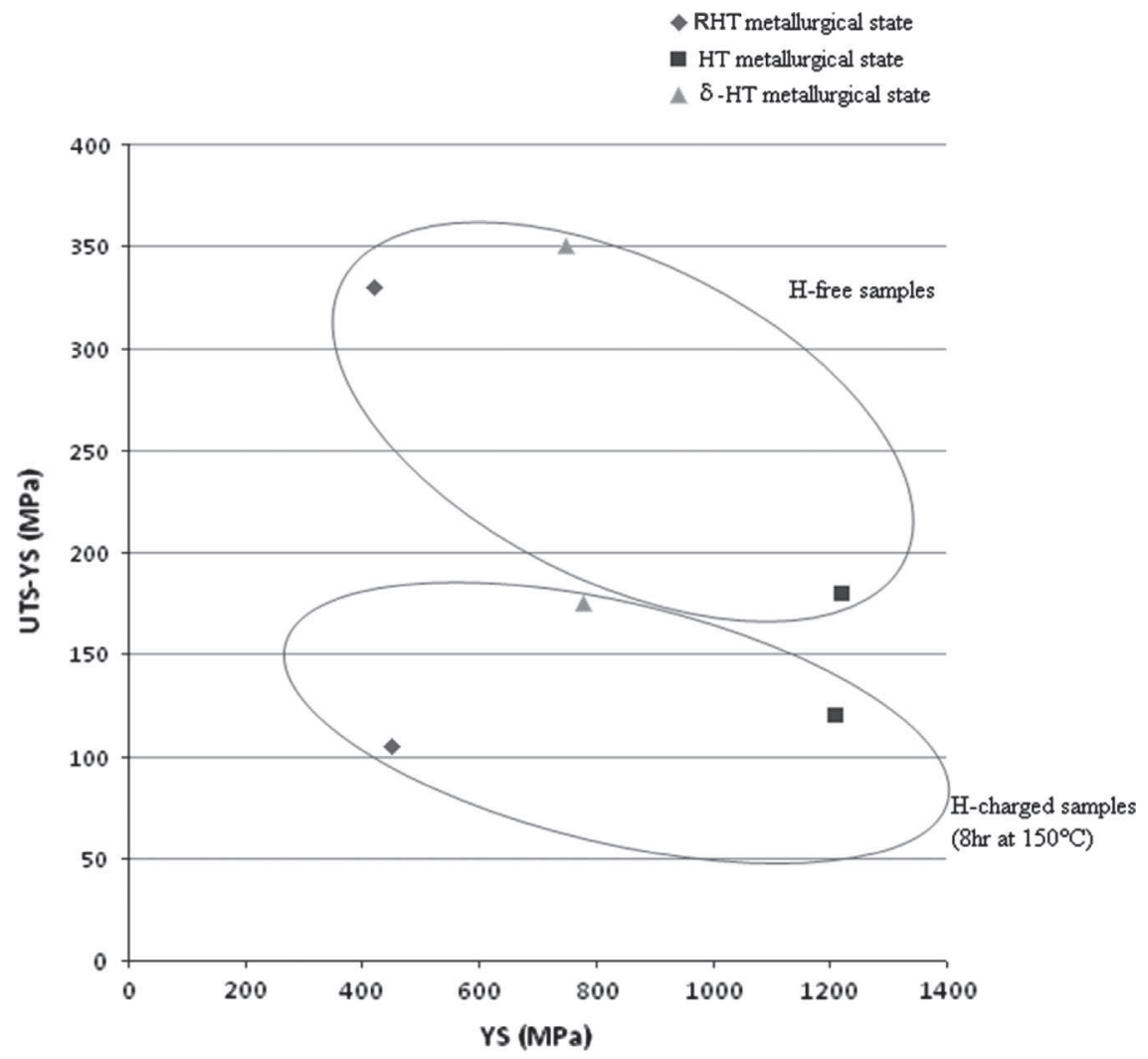

Fig. 8. Evolution of UTS-YS as a function of YS for H-free and H-charged samples of RHT, HT and $\delta$-HT metallurgical states. 
performed on hydrogenated samples demonstrated that grain boundaries were identified as mechanical "fuses" for the RHT metallurgical state, $\gamma^{\prime}-\gamma^{\prime \prime} /$ matrix interfaces for the HT metallurgical state and $\gamma^{\prime}-\gamma^{\prime \prime} /$ matrix and $\delta /$ matrix interfaces for the $\delta$-HT metallurgical state. The existence of interactions between plasticity and hydrogen could also be considered, a notion that will be discussed in greater detail later in this paper.

Given that alloy 718 is widely used in industry in the HT metallurgical state under high-temperature conditions, it was interesting to characterize the effect of temperature on $\mathrm{HE}$ susceptibility and hydrogen-trapping reversibility for this type of metallurgical state. This aspect was studied by performing tensile tests at different temperatures in relation to the different desorption heat treatments presented previously in this paper.

\subsection{Effect of temperature on HE susceptibility and hydrogen- trapping reversibility}

To study the effect of temperature on the HE susceptibility of alloy 718 , tensile tests were performed at different temperatures and for an intermediate strain rate of $5 \times 10^{-4} \mathrm{~s}^{-1}$. The results of these tests are presented in Table 5 , as well as the hydrogen content measured before and after the tensile tests.

Based on the results of the desorption heat treatments and the very short duration of the tensile tests (varying from 12 to $180 \mathrm{~s}$ ), the hydrogen content can be considered to remain constant during mechanical tests. A significant loss of elongation to failure was observed for all hydrogenated samples tested at low temperatures $\left(<150{ }^{\circ} \mathrm{C}\right.$ ) compared to the $\mathrm{H}$-free samples with a $\mathrm{HE}$ sensitivity factor between $80 \%$ and $95 \%$. At $320{ }^{\circ} \mathrm{C}$, a decrease in elongation to failure was also observed for hydrogenated samples, but the hydrogen effect was less noticeable, with, in this latter case, an HE sensitivity factor of only $38 \%$. Moreover, regardless of the temperature, the yield stress and ultimate tensile strength appeared to remain unaffected by hydrogen.

The corresponding fracture surfaces are presented in Fig. 9. Predominant brittle fracture by cleavage was observed in relation to the presence of $\gamma^{\prime}$ and $\gamma^{\prime \prime}$ precipitates. The more elevated the temperature was, the less fracture by cleavage was observed in favor of transgranular ductile rupture with surfaces covered by nano-dimples (Fig. 9e). Nevertheless, alloy 718 in the HT metallurgical state still remains mechanically embrittled by hydrogen at $320^{\circ} \mathrm{C}$ according to the results of Wei [11].

For a better understanding of the effect of temperature on HE, the evolution of $\varepsilon_{f}$ and curves of strain-hardening vs. temperature are presented in Figs. 10 and 11 for $\mathrm{H}$-free and pre-hydrogenated samples associated with the rupture modes observed by SEM. It is shown that the contribution of strain-hardening in reaching the fracture stress of the weakest traps was not affected by the testing temperature for the hydrogenated samples.
All of the aforementioned results and observations suggest that up to $150{ }^{\circ} \mathrm{C}$, the rupture mode was controlled by transgranular rupture due to the local segregation of hydrogen on $\{111\}$ planes, inducing cleavage, and to the decohesion of particles/matrix interfaces. Beyond $150{ }^{\circ} \mathrm{C}$, the rupture became ductile. However, this rupture was not conventional. Indeed, the presence of nanodimples on rupture surfaces was observed. These nano-dimples must be related to the very thin strengthening particles of $\gamma^{\prime \prime}$ and $\gamma^{\prime}$. These particles were homogeneously distributed in the matrix. At $300{ }^{\circ} \mathrm{C}$, the critical stress inducing cleavage, and $\gamma^{\prime \prime}-\gamma^{\prime} /$ matrix interface decohesion was not reached in the elastic regime. Localization of the deformation in slip bands and finally at the onset of necking was required to trigger a ductile fracture process on a set of particles including the rupture of $\gamma^{\prime \prime}-\gamma^{\prime} /$ matrix interfaces. This particular ductile fracture surface with small dimples was previously observed by Wei [11] under air testing conditions at $300^{\circ} \mathrm{C}$ and $600{ }^{\circ} \mathrm{C}$.

Concerning the disappearance of intergranular rupture, desorption could be induced, but the hydrogen content measurements indicate that hydrogen desorption during the tensile test was very limited. Finally, to explain the fact that the critical stress inducing intergranular rupture was not reached at $300{ }^{\circ} \mathrm{C}$, a decrease in the hydrogen content at grain boundaries could be assumed, which might be due to the relocalization of hydrogen through the bulk material. Nevertheless, this hypothesis requires further investigation to be confirmed.

\subsection{Hydrogen-plasticity interactions. Effect of the strain rate on HE}

One way to study hydrogen-dislocation interactions consists in performing tensile tests at different strain rates. A slow strain rate was already applied to determine the HE susceptibility of the different metallurgical states at room temperature in the experiments discussed in the first part of this paper. Thus, a higher strain rate, i.e., $1 \times 10^{-1} \mathrm{~s}^{-1}$, was tested, and the results were compared to those obtained previously (Table 6). Samples were cathodically hydrogenated under the same conditions, i.e., for $8 \mathrm{~h}$ at $150{ }^{\circ} \mathrm{C}$, because this precharging was sufficient to ensure the saturation of active hydrogen traps.

Fig. 12 presents the evolution of the elongation to failure $\varepsilon_{f}$ vs. ultimate tensile strength at different strain rates for the RHT, HT and $\delta$-HT metallurgical states.

It was observed that the HE susceptibility decreased as the strain rate increased for the HT metallurgical state. Generally, most studies have attributed this observation to an interaction between hydrogen and dislocations. For example, Tien et al. [28] related the dislocation velocity above which a dislocation will break free of its hydrogen atmosphere to a critical strain rate. Fournier et al. showed that at slow strain rates, dislocation sweeping of hydrogen occurred and hydrogen embrittlement was more pronounced [8]. For a strain rate of $5 \times 10^{-3} \mathrm{~s}^{-1}$, the dislocation velocity was too

Table 5

Mechanical properties at room temperature (RT), $80^{\circ} \mathrm{C}, 150^{\circ} \mathrm{C}$ and $320^{\circ} \mathrm{C}$ of $\mathrm{H}$-free and hydrogenated specimens and corresponding hydrogen content (HT metallurgical state).

\begin{tabular}{|c|c|c|c|c|c|c|}
\hline Temperature of tensile tests & $\varepsilon_{f}(\%)$ & YS (MPa) & UTS (MPa) & $I_{E}(\%)$ & \multicolumn{2}{|c|}{ Average hydrogen content (wt ppm) } \\
\hline \multicolumn{7}{|l|}{ H-free } \\
\hline $\boldsymbol{T}=\mathbf{2 5}{ }^{\circ} \mathrm{C}$ & 19 & 1220 & 1400 & & $0.9( \pm 0.2)$ & \\
\hline $\mathbf{T}=\mathbf{8 0}{ }^{\circ} \mathrm{C}$ & 16 & 1240 & 1410 & & & \\
\hline$T=150{ }^{\circ} \mathrm{C}$ & 15 & 1240 & 1400 & & & \\
\hline$T=320{ }^{\circ} \mathrm{C}$ & 14.5 & 1130 & 1260 & & & \\
\hline H-charged $\left(8 \mathrm{~h}\right.$ at $\left.150{ }^{\circ} \mathrm{C}\right)$ & & & & & Before tensile test & After tensile test \\
\hline$T=25{ }^{\circ} \mathrm{C}$ & 0.6 & 1210 & 1330 & $97 \%$ & $58( \pm 4)$ & $55( \pm 5)$ \\
\hline $\mathbf{T}=\mathbf{8 0}{ }^{\circ} \mathrm{C}$ & 0.8 & 1195 & 1310 & 95\% & & $55( \pm 6)$ \\
\hline$T=150{ }^{\circ} \mathrm{C}$ & 3.5 & 1230 & 1350 & $78 \%$ & & $53( \pm 5)$ \\
\hline$T=320^{\circ} \mathrm{C}$ & 9 & 1250 & 1365 & $38 \%$ & & $47( \pm 3)$ \\
\hline
\end{tabular}



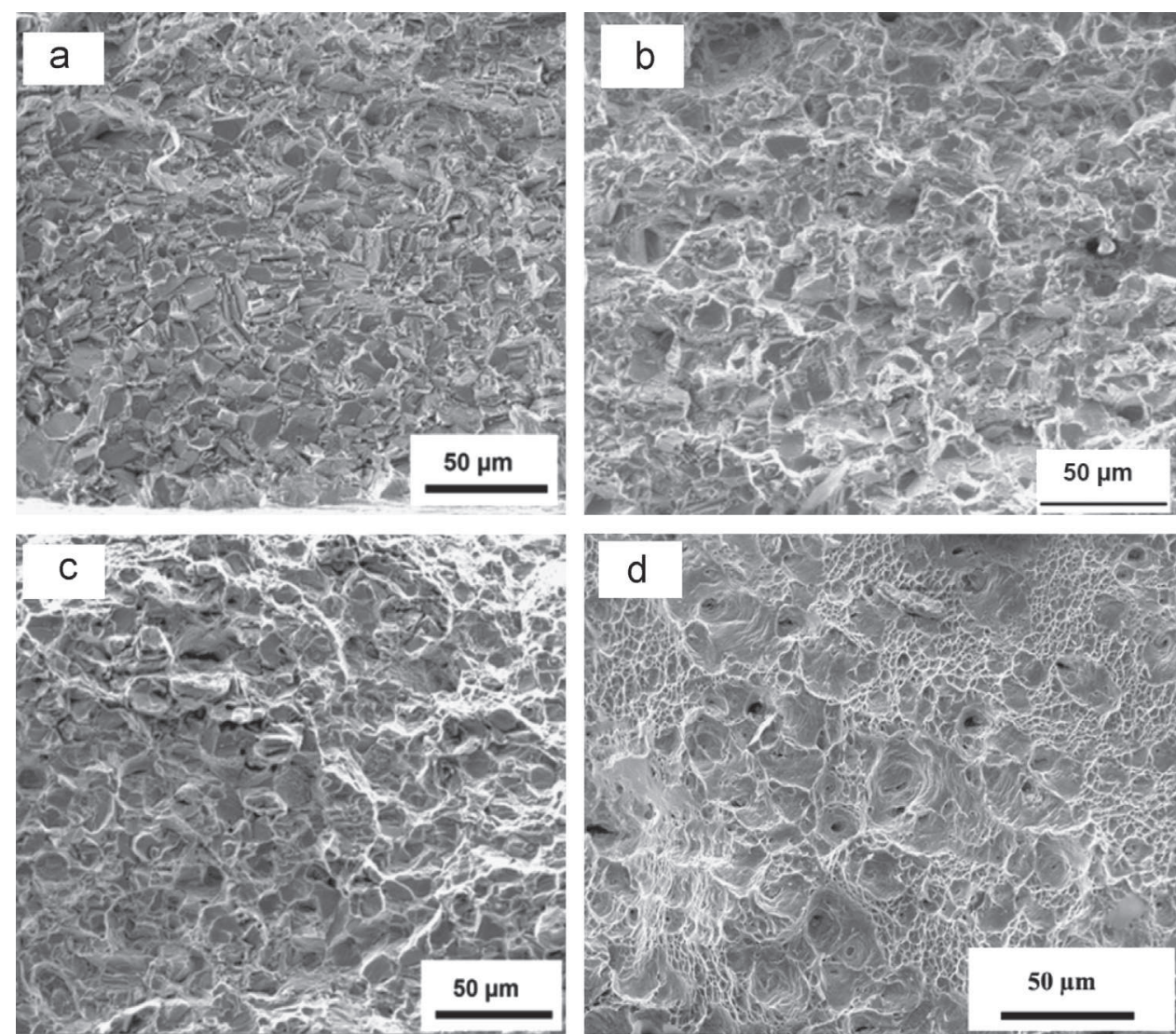

Fig. 9. Fracture surfaces observations made by SEM of hydrogen precharged HT metallurgical state at (a) $25^{\circ} \mathrm{C}$, (b) $80^{\circ} \mathrm{C}$, (c) $150^{\circ} \mathrm{C}$ and (d) $320^{\circ} \mathrm{C}\left(5 \times 10^{-4} \mathrm{~s}^{-1}\right)$.

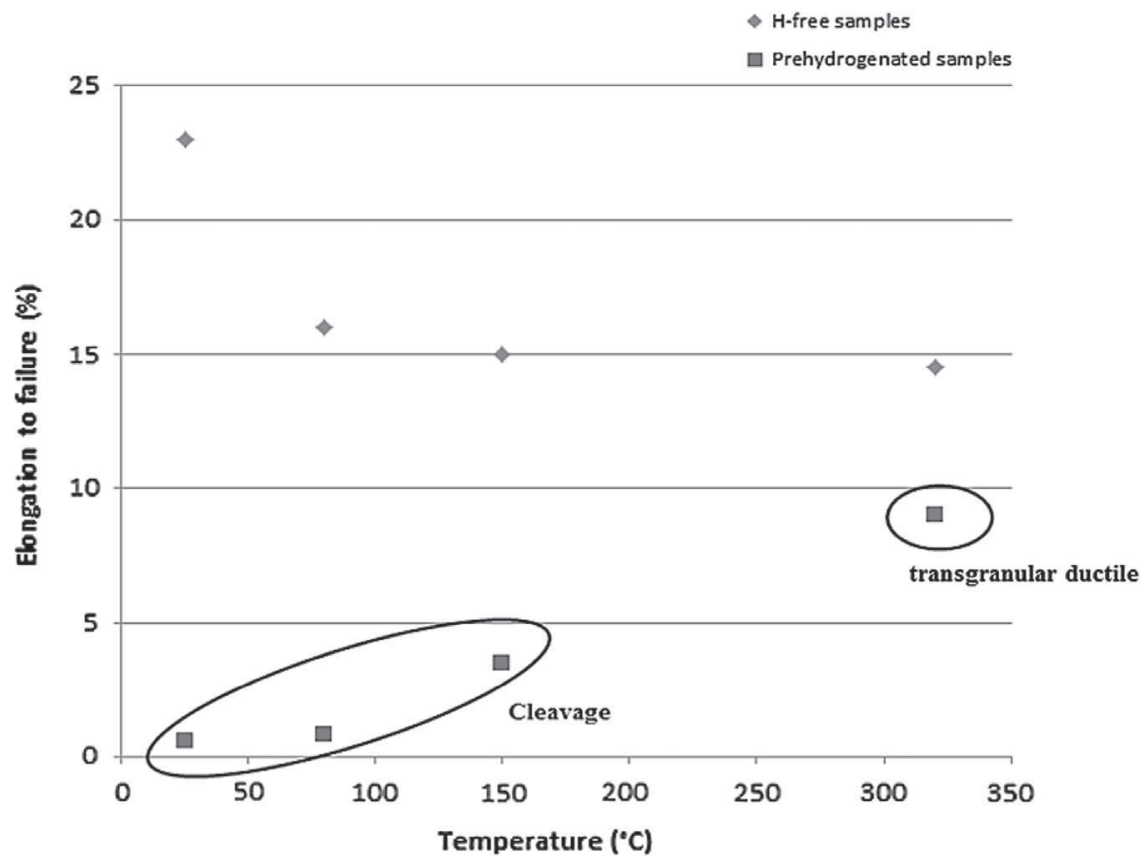

Fig. 10. Evolution of $\varepsilon_{f}$ vs. temperature for $\mathrm{H}$-free and pre-hydrogenated samples.

high to allow hydrogen segregation to dislocations and hydrogen embrittlement disappeared.

In this study, the same trends were observed. However, at a high strain rate of $1 \times 10^{-1} \mathrm{~s}^{-1}$, under which hydrogen transport by dislocations is negligible, HE still occurred. In fact, hydrogen transport by dislocations was not observed to be an active mechanism in this study because the cathodic charging applied was sufficient to induce the saturation of active hydrogen traps. The high strain rate essentially induced a modification of the deformation mode in the HT and $\delta$-HT metallurgical states, i.e., an increase in the number of glide planes and a decrease in the glide inter-band spacing, which led to a decrease in strain localization. 


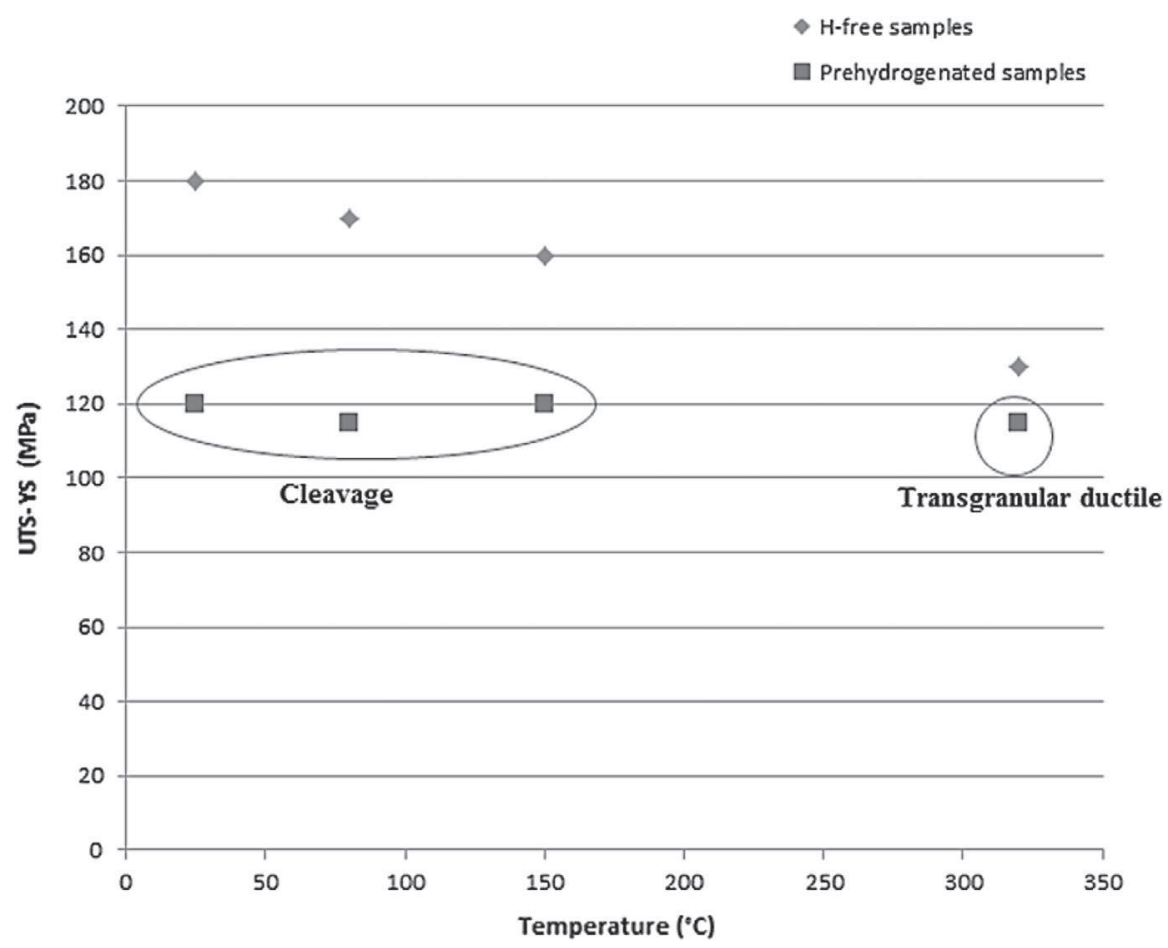

Fig. 11. Evolution of strain-hardening vs. temperature for $\mathrm{H}$-free and pre-hydrogenated samples.

Table 6

Mechanical properties and embrittlement index at room temperature of hydrogenated $\left(5 \mathrm{~h}\right.$ at $\left.150{ }^{\circ} \mathrm{C}\right)$ specimens of alloy 718 in RHT, HT and $\delta$-HT, metallurgical states for two strain rates $\left(5 \times 10^{-4} \mathrm{~s}^{-1}\right.$ and $\left.1 \times 10^{-1} \mathrm{~s}^{-1}\right)$.

\begin{tabular}{|c|c|c|c|c|c|c|c|c|}
\hline \multirow[t]{2}{*}{ Metallurgical state } & \multicolumn{4}{|c|}{$\dot{\varepsilon}=5 \times 10^{-4} \mathrm{~s}^{-1}$} & \multicolumn{4}{|c|}{$\dot{\varepsilon}=1 \times 10^{-1} \mathrm{~s}^{-1}$} \\
\hline & $\varepsilon_{f}(\%)$ & YS (MPa) & UTS (MPa) & $I_{E}(\%)$ & $\varepsilon_{f}(\%)$ & YS (MPa) & UTS (MPa) & $I_{E}(\%)$ \\
\hline RHT & 2.2 & 450 & 555 & 95 & 10 & 460 & 620 & 82 \\
\hline HT & 0.6 & 1210 & 1330 & 97 & 11 & 1190 & 1390 & 45 \\
\hline$\delta$-HT & 1.0 & 780 & 955 & 96 & 8.5 & 790 & 830 & 55 \\
\hline
\end{tabular}

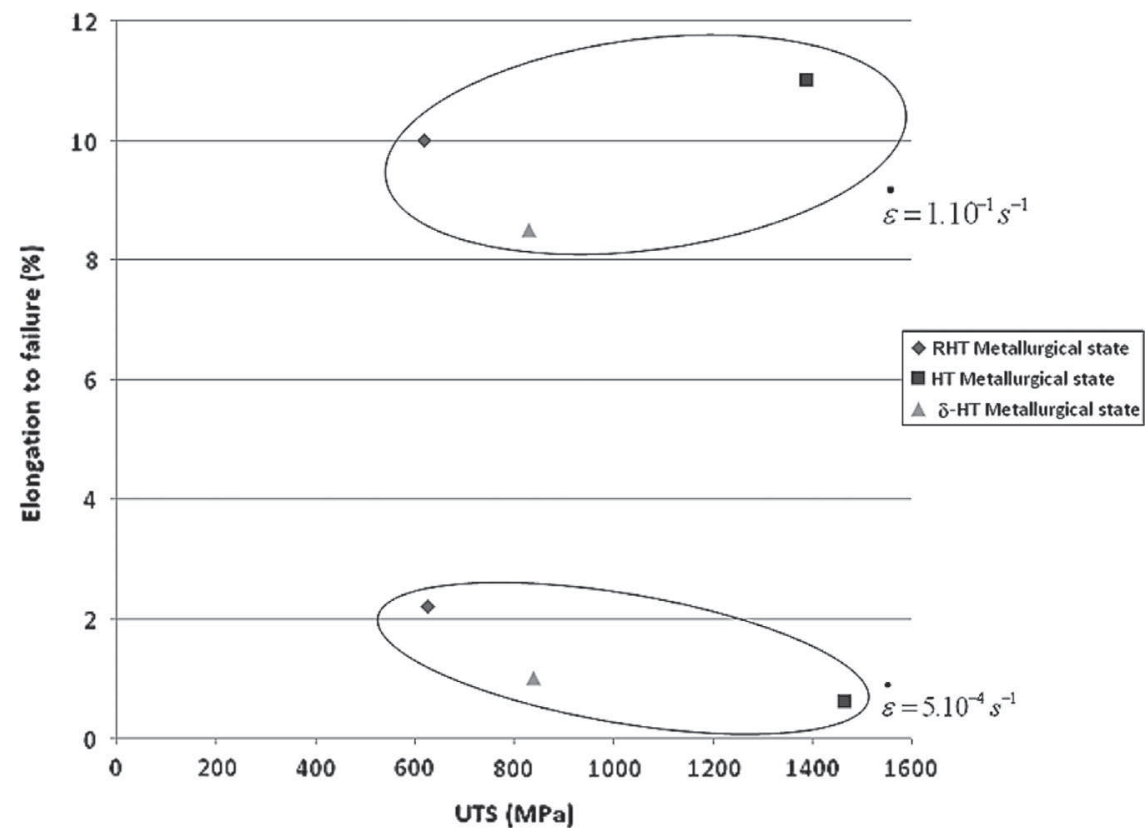

Fig. 12. Evolution of elongation to failure vs. UTS for H-charged samples tested at two strain rates, i.e., $5 \times 10^{-4} \mathrm{~s}^{-1}$ and $1 \times 10^{-1} \mathrm{~s}^{-1}$, for RHT, HT and $\delta$-HT metallurgical states. 

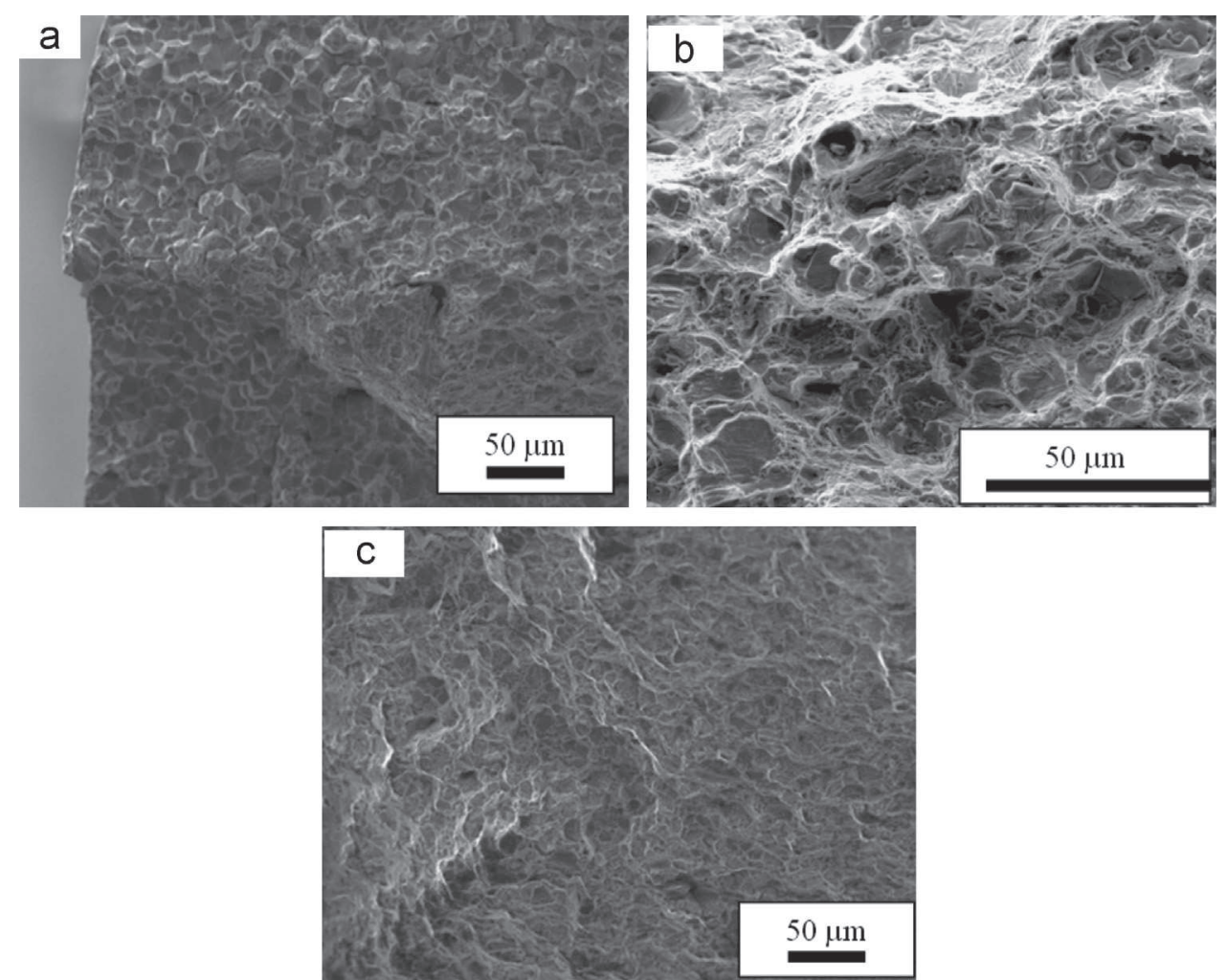

Fig. 13. Tensile fracture surfaces of hydrogenated samples $\left(5 \mathrm{~h}\right.$ at $150{ }^{\circ} \mathrm{C}$ ) tested at $1 \times 10^{-1} \mathrm{~s}^{-1}$ : (a) RHT metallurgical state, (b) HT metallurgical state and (c) $\delta$-HT metallurgical state.

The fracture surfaces obtained after the tensile tests performed at a high strain rate were compared to the fracture surfaces of tensile samples tested at a low strain rate (Fig. 13).

SEM imaging of the fracture surfaces showed that the presence of cleavage and interfaces decohesion was reduced, for the benefit of a ductile fracture for the HT and $\delta$-HT metallurgical states. As in the tensile tests performed at $320^{\circ} \mathrm{C}$, nano-scale dimples were observed in the brittle areas for the HT metallurgical state. However, for the RHT metallurgical state, which was the state most affected by hydrogen at a strain rate of $1 \times 10^{-1} \mathrm{~s}^{-1}$, the surface presented intergranular rupture similar to that observed at a strain rate of $5 \times 10^{-4} \mathrm{~s}^{-1}$.

All of these observations are consistent with the previous discussion regarding the decrease in strain localization and ultimately fewer mechanically generated $\gamma^{\prime \prime}-\gamma^{\prime}$ and $\delta /$ matrix interfaces enriched in hydrogen leading to a ductile rupture with fewer cleavage facets. The fact that the $\delta$-HT metallurgical state is more susceptible to HE at a high strain rate is probably due to the size of $\delta$ particles, which offsets the decrease in strain localization relative to that of very thin $\gamma^{\prime \prime}-\gamma^{\prime}$ particles. Concerning the RHT metallurgical state, i.e., the most susceptible to HE, intergranular rupture remained the main fracture mode. This result suggested that, even if strain localization induced by strengthening particle shearing did not occur for this state, the strain localization was enough to reach the critical stress required to induce intergranular rupture (see Fig. 7) during the tensile tests performed at $1 \times 10^{-1} \mathrm{~s}^{-1}$.

\section{Conclusion}

The results of this study demonstrate that Ni-based superalloy 718 was strongly susceptible to $\mathrm{HE}$ from $25^{\circ} \mathrm{C}$ to $300^{\circ} \mathrm{C}$. The results highlight the major role played by hydrogen solubility in the HE of the alloy and the impact of metallurgical state on the alloy's HE susceptibility.

The main conclusions of this work are as follow:

- Grain boundary embrittlement by hydrogen requires a high $\mathrm{Nb}$ content in the matrix and/or a high stress level induced by the localization of deformation.

- $\gamma^{\prime \prime}-\gamma^{\prime} /$ matrix and $\delta /$ matrix interfaces presented high mechanical resistance but nevertheless were susceptible to hydrogen embrittlement, including at high temperature, at which point they "broke" due to a high critical stress level.

- For the HT metallurgical state, the rupture mode varied from intergranular to transgranular brittle and transgranular ductile rupture, but fracture was always localized on the active glide planes to which hydrogen preferentially segregated.

- In this work, hydrogen transport was not a necessary mechanism for enhancing hydrogen trapping given that cathodic precharging was performed such that hydrogen traps were saturated and hydrogen solubility was high.

\section{Acknowledgments}

This work was granted access to the HPC resources of CALMIP (CICT Toulouse, France) under the allocation 2014-p0912. The authors thank Joël Alexis (ENI de Tarbes) for FEG-SEM observations and Marie-Christine Lafont (CIRIMAT) for TEM observations.

\section{References}

[1] J.M. Oblak, D.F. Paulonis, D.S. Duvall, Metall. Trans. 5 (1974) 143-153. [2] Y. Huang, T.G. Langdon, J. Mater. Sci. 42 (2007) 421-427. 
[3] N. Totsuka, E. Lunarska, G. Cragnolino, Z. Szklarska-Smialowska, Corrosion 43 (1987) 505-514.

[4] F Lecoester, J. Chene, D Noel, Mater. Sci. Eng A 262 (1999) 173-183.

[5] J. Chene, A.M. Brass, Metall. Mater. Trans. A35 (2004) 457-464.

[6] D.M. Symons, J. Nucl. Mater. 265 (1999) 225-231.

[7] P.D. Hicks, C.J. Altstetter, Metall. Trans. A21 (1990) 365-372.

[8] L. Fournier, D. Delafosse, T. Magnin, Mater. Sci. Eng. A 269 (1999) 111-119.

[9] P.D. Hicks, C.J. Altstetter, Metall. Trans. A23 (1992) 237-249.

[10] S. Fukuyama, K. Yokogawa, Effect of Heat Treatments on Hydrogen Environment Embrittlement of Alloy 718, in: Superalloys 718, 625, 706 and Various Derivatives, Pittsburgh, 1994, pp. 807-816.

[11] W. Wei, The Effect of Hydrogen on the High Temperature Mechanical Properties of IN 718, in: Superalloys 718, 625, 706 and Various Derivatives, Pittsburgh, 1997, pp. 705-714.

[12] L. Liu, C. Zhai, C. Lu, W. Ding, A. Hirose, K.F. Kobayashi, Corros. Sci. 47 (2005) 355-367.

[13] G. Sjoberg, D. Cornu, Hydrogen Embrittlement of Cast Alloy 718 effects of Homogeneization, Grains Size and $\delta$-Phase, in: Superalloys 718, 625, 706 and Various Derivatives, Pittsburgh, 2001, pp. 679-690.

[14] L. Liu, K. Tanaka, A. Hirose, K.F. Kobayashi, Sci. Technol. Adv. Mater. 3 (2002) 335-344.

[15] G.A. Young, J.R. Scully, Scr. Mater. 36 (1997) 713-719.

[16] W.M. Robertson, Metall. Trans. A8 (1977) 1709-1712.

[17] B.G. Pound, Corros. Sci. 42 (2000) 1941-1956.

[18] C. Larignon, J. Alexis, E. Andrieu, G. Odemer, C. Blanc, Corros. Sci. 69 (2013) 211-220.
[19] D. Connetable, G. Galliano, G. Odemer, C. Blanc, E. Andrieu, J. Alloys Compd. 610 (2014) 347-351.

[20] H.K. Birnbaum, I.M. Robertson, P. Sofronis, D. Teter, Mechanisms of hydrogen related fracture - a review, in: T. Magnin (Ed.), Proceeding of the Second International Conference on Corrosion-Deformation Interactions, The Institute of Materials, Nice, France, 1996, pp. 172-195.

[21] P.J. Ferreira, I.M. Robertson, H.K. Birnbaum, Acta Mater. 46 (1998) 1749-1757.

[22] N.R. Moody, M.W. Perra, S.L. Robinson, Hydrogen-induced cracking in an ironbased superalloy, in: N.R. Moody, A.W. Thompson (Eds.), Hydrogen Effects in Material Behavior, 1990, pp. 625-634.

[23] S.L. Robinson, B.P. Somerday, N.R. Moody, Hydrogen embrittlement of stainless steel, in: Proceedings of the 11th International Conference on Fracture, Turin, Italy, 2005, p. 672

[24] A. Turnbull, R.G. Ballinger, I.S. Hwang, M.M. Morra, M. Psaila-Dombrowski, R. M. Gates, Metall. Trans. 23A (1992) 3231-3244.

[25] D.H. Lassila, H.K. Birnbaum, Acta Metall. 35 (1987) 1815-1822.

[26] G.S. Was, Corrosion 46 (1990) 319-330.

[27] T. Yonezawa, K. Onimura, O. Sakamoto, N. Sasaguri, H. Nakata, H. Susukida, in: Proceedings of the International Symposium on Environmental Degradation of Materials in Nuclear Power Systems Water Reactors, NACE, Houston, TX, 1984, pp. 345-366.

[28] M.T. Miglin, H.A. Domain, in: R.C. Scarberry (Ed.), Corrosion of Nickel-Base Alloys, ASM International, Materials Park, OH, 1985, pp. 147-164.

[29] J.K. Tien, A.W. Thompson, I.M. Bernstein, R.J. Richards, Metall. Trans. A7 (1976) $821-829$. 